\title{
THE PROPOSAL TO CREATE PROVISIONS OF LAND MILITARY EQUIPMENT IN THE ARMY OF THE CZECH REPUBLIC
}

\author{
Jaromir MARES, Petr KRIZEK, Vaclav ZAJICEK, Jan HUSAK \\ University of Defence, Brno, The Czech Republic \\ jaromir.mares@unob.cz
}

\begin{abstract}
The paper deals with the proposed method of creating the reserves of land military equipment in the Army of the Czech Republic. The aim is to propose the classification of spare parts categories and their consumption quantities in a calendar year. The reserves optimization criteria and the Pareto ABC analysis have been employed, besides basic methods, in the submitted paper. The proposal is based on the purpose and delivery time of spare parts. The cost indicator is related to the operation of land military equipment within its life cycle, including the supply of spare parts. Under the above mentioned conditions the method was determined to create the reserves of spare parts for land military equipment necessary to ensure the ACR operability in peacetime.
\end{abstract}

Keywords: Pareto analysis, reserves, spare parts,

\section{Introduction}

In recent years, great attention has been paid to the search for economic savings within the Ministry of Defence (hereinafter referred to as MoD) and the efficiency assessment of individual organizational entities and processes has been implemented. During the search for savings and efficiency, the cost assessment of activities is introduced to determine actual costs. The conversion is related to the performance unit at the level of planned costs so that the cost effectiveness can be maintained.

Costs rank among key performance indicators, which are an element for monitoring and assessing the performance of the accounting entities [1]. In the performance of the MoD activities, cost effectiveness represents especially the total costs related to the operation of land military equipment within its life cycle, particularly, in providing spare parts. The life cycle costs (LCC) consist of all direct costs and variable overhead costs related to the stages of the life cycle of the said system [2].

Various measures, such as the rationalization of processes, the restructuring of working methods or the introduction of standards, e.g. the standards for training, exercises, consumption or a financial planning, calculation unit may include saving of financial resources. The basic concepts of the issue concerned include the economy, efficiency and expediency to ensure an optimal level of the attainment of objectives in carrying out appointed tasks, without the occurrence of undesirable phenomena [3], [4].

Costs are perceived as a monetary valuation and a resulting sacrifice of scarce resources to perform some activities [4]. The evaluation of expended costs itself regarding the supply system in the provision of spare parts is a complex process. 
It is dependent on the proper management and evaluation of data on actual expenditures for the purchase of spare parts and services for the benefit of the delivery, storage and maintenance of spare parts. The personnel costs are also an integral part of the total costs.

The evaluation criteria are determined based on the established and objective facts. The criteria should be transparent and structured according to the specific conditions with regard to the scope or functionality [4]. The criteria of costs allow the measurement of the amount of resources consumed within the supply system of spare parts and their comparison with the planned inputs or defined standards.

\section{The present state of the theory of stockpiling related to spare parts}

In the past, the term "supply" was used within the MoD on a long-term basis as well as the supply system comprising a process of the build-up and maintenance of supplies and their distribution to cost centres.

\subsection{Provision of spare parts}

Currently, the term "reserve" is used. A reserve means a set quantity of movable property items to support property requirements, which result from performing the functions of the MoD [6]. Since the issue of the mentioned order, the property manager's directive has not been updated yet and, thus, the stockpiling has been following the said directive up to the present [7].

Currently, there is no functional system in the Army of the Czech Republic (hereinafter referred to as ACR) to provide spare parts from the central warehouses of the ACR. [9] At the end of the 1990s, the hacking into the functioning system to provide spare parts occurred. This undermined the acquisition process of spare parts considerably. In 2002, the central acquisition of spare parts almost stopped.

\subsection{Analysis of spare part consumption} After 2004, the situation improved in the older established equipment. Over the last 3 years, experts have analysed the consumption of spare parts. The analysis applied to the spare parts issued from central warehouses as well as all the spare parts acquired for immediate consumption. Due to the imprecisely defined responsibilities for planning financial resources, the growing trend failed to be maintained.

In 2009, the policy for planning the spare part requirement was proposed and approved on the basis of the forwardlooking operation and maintenance plans and planning the repair activities of repair units. Based on planning the financial resources by individual consumers and by a central element, an adequate level of financial resources was secured. After that, experts prepared the specifications for the procurement of spare parts centrally with a non-central performance for selected types of equipment for the period of $2-4$ years. This, however, failed to be applied to the extremely expensive spare parts supplied from abroad.

\subsection{Improvement in the provision of spare parts}

To improve the provision of spare parts for the land military equipment of usual needs, the principle of stockpiling to support combat operations can be used in implementing the "inventory optimization". From 2005 to 2011, the expert property authorities created the standards of the spare part inventory needed for the required maintenance of individual types of land military equipment. They result from the technological maintenance procedures, from the physical wear of equipment and from technological capabilities of repair units at a given level. The spare parts consumed in more frequent repairs over the past 3 years were also included in the maintenance standards of a higher level. For stockpiling to support combat operations, the so-called Standard Day of Supply (SDOS) as well as the spare parts 
for the anticipated repairs caused by damage to the land military equipment were included, besides the abovementioned standards. For the reason mentioned, it is necessary to deal with the optimization of spare part stockpile of usual needs together with the spare part stockpile to support combat operations. Only in this way, the total of spare part stockpile can be objectively optimized. Their expiration has also to be monitored effectively. The size of the spare part stockpile to support combat operations has still been given by 7 SDOS in a unit and 23 SDOS in the central warehouse.

\subsection{The optimal level of stockpile and the level of risk}

To determine the optimal level of spare part stockpile to meet usual needs is the hardest thing in a given field. In the past, it resulted only from the analysis of consumption based on the previous period. The access to the optimization of spare part stockpile is dependent on defining the availability of individual items of spare parts. To support the combat readiness of units, the technical readiness coefficient has been defined for selected equipment, which is $85 \%$ regarding combat equipment [11].

Due to the unavailability of spare parts, the losses caused by the insufficient level of forces proficiency (inexperience) or by insufficient support of combat readiness may occur. In case of the employment in an operation, the consequences may be much more serious - failure of the combat mission. The aim of optimizing the spare part stockpile is to minimize their quantity to be available at very short (immediate) notice from external suppliers. Minimizing the stockpile is, however, in the direct conflict with the risk level of its unavailability. When the information system is used properly, it would be a realistic goal. The risk level of spare part unavailability from external suppliers is too high because the standard delivery time of spare parts for special equipment is 6 up to 24 months from signing the contract. The lack can be eliminated through the required amount of stockpile in the unit's warehouse or, if need be, in the central warehouse.

\subsection{Consumption criterion for spare parts}

The nature of spare part consumption is an important criterion for optimizing the stockpile of spare parts in maintenance. From the viewpoint of the MoD, the situation is not fully satisfactory because the overall life time of the land military equipment is much shorter than the overall life time of vehicles and machinery in the civil sector. For the MoD it is adequate to use the so-called management segmentation of spare part items according to the appropriate criteria for optimizing the stockpile of spare parts as follows:

- According to the frequency of consumption;

- According to availability;

- According to delivery times [9].

The goal is to effectively divide a large complex of consumption data of spare parts into groups (segments) requiring a different approach when optimizing, especially requiring the specifics in the stockpile planning and management.

Then, it is necessary to carry out prediction of consumption in relation to the consumption and the plans for the use and maintenance. It is important to differentiate the consumption of spare parts for planned maintenance and repairs and the consumption of spare parts for unplanned repairs. The final step is to perform the stockpile optimization itself according to the results of mathematical optimization methods with regard to the high expertise of the operations personnel themselves. It is mainly their internal opinion of the requirement for spare parts [10].

\section{Categorization of spare parts}

When using the Pareto (ABC) analysis to determine the level of spare part stockpile required for land military equipment, it is necessary to use the categorization of spare parts. The proposal for the categorization of 
spare parts was carried out based on their prices [13]. The said categorization for the needs of the MoD does not have an appropriate informative value. It is necessary to deal with the repairs of land military equipment from three different perspectives, i.e. according to the consumption in a calendar year, according to the purpose of consumption and according to the time of delivery to a unit. The categorization of spare parts is given in Table 1 as follows.

Table 1: Categorization of spare parts

I. According to the consumption in a calendar year

\begin{tabular}{|l|l|l|}
\hline \multirow{2}{*}{} & Category A & Includes spare parts representing 80\% of consumption \\
\cline { 2 - 3 } & Category B & Includes spare parts representing 10-15\% of consumption \\
\cline { 2 - 3 } & Category C & Includes spare parts representing 1-10\% of consumption \\
\cline { 2 - 3 } & Category D & Includes spare parts representing 0\% of consumption \\
\hline \multicolumn{2}{|c|}{ II. According to the purpose of consumption } \\
\hline \multirow{4}{*}{} & Category A & Spare parts for planned (prescribed) maintenance \\
\cline { 2 - 3 } & Category B & Spare parts for repairs (remedial maintenance), \\
\cline { 2 - 3 } & Category C & Spare parts for the other and special types of maintenance \\
\hline \multirow{2}{*}{ II. According to the time of delivery of a spare part the ACR installations } \\
\hline \multirow{3}{*}{} & Category A & Up to 48 hours \\
\cline { 2 - 3 } & Category B & Up to 6 months \\
\cline { 2 - 3 } & Category C & Up to 12 months \\
\cline { 2 - 3 } & Category D & More than 12 months \\
\hline
\end{tabular}

A given time interval does not include the time required for the acquisition activity since the conclusion of long-term basic contracts is assumed.

The existing logistics information system enables the provision of data for the first two categorizations. The categorization according to the time of delivery can be performed manually based on the previous experience and data from the contracts already concluded.

Within the scope of the project relating to the acquisition of the wheeled fighting vehicle - Pandur II $8 \times 8 \mathrm{CZ}$, the direction for the consumption of spare parts for maintenance and repairs carried out by troop teams at all levels has been delivered. The direction contains the total of 213 items of spare parts to ensure the operability of 72 vehicles over a period of 1 year. Of the number of items there are 23 items intended for the $1^{\text {st }}$ level; 13 items for the $2^{\text {nd }}$ level; 74 items for the $3^{\text {rd }}$ level and 101 items for the $4^{\text {th }}$ level. [14]

In total, 2,000 items marked as spare parts are catalogued to ensure the operability of the equipment mentioned to meet the needs of the MoD. Unfortunately, the items of intangible property are also included in this category. They are e.g. the accompanying and operational documentation, tools, products for maintenance and repairs, teaching and training aids, the equipment of vehicles and ammunition.

Within the reporting of spare part consumption, 370 pieces of spare parts in 33 items were consumed in the implementation of technical maintenance (TM-1) from 2013 to 2016, (see Table 2). 
Table 2: The list of spent spare parts of wheeled infantry combat vehicle during TM-1

\begin{tabular}{|l|c|c|c|c|c|}
\hline Spare part & $\mathbf{2 0 1 3}$ & $\mathbf{2 0 1 4}$ & $\mathbf{2 0 1 5}$ & $\mathbf{2 0 1 6}$ & Total \\
\hline GEAR OIL FILTER & 7 & 6 & 12 & 10 & 35 \\
\hline FUEL FILTER & & & 3 & 1 & 4 \\
\hline EC ENGINE FUEL FILTER & & 4 & & & 4 \\
\hline 444F BRAKE PADS & 2 & 2 & & & 4 \\
\hline 456F BRAKE PADS & 3 & 15 & & 2 & 20 \\
\hline $\begin{array}{l}\text { DCA4 FILTER - LARGE } \\
\text { GUFERO 547716001201 ..... } \\
\text {..etc. }\end{array}$ & & & & 8 & 8 \\
\hline Number of realized (TM-1) & 34 & 36 & 22 & 25 & 117 \\
\hline
\end{tabular}

In 2016, the consumption of only 18 items of spare parts with a total consumption of

percentage of spare part consumption.

77 pieces was recorded. Chart 1 shows the

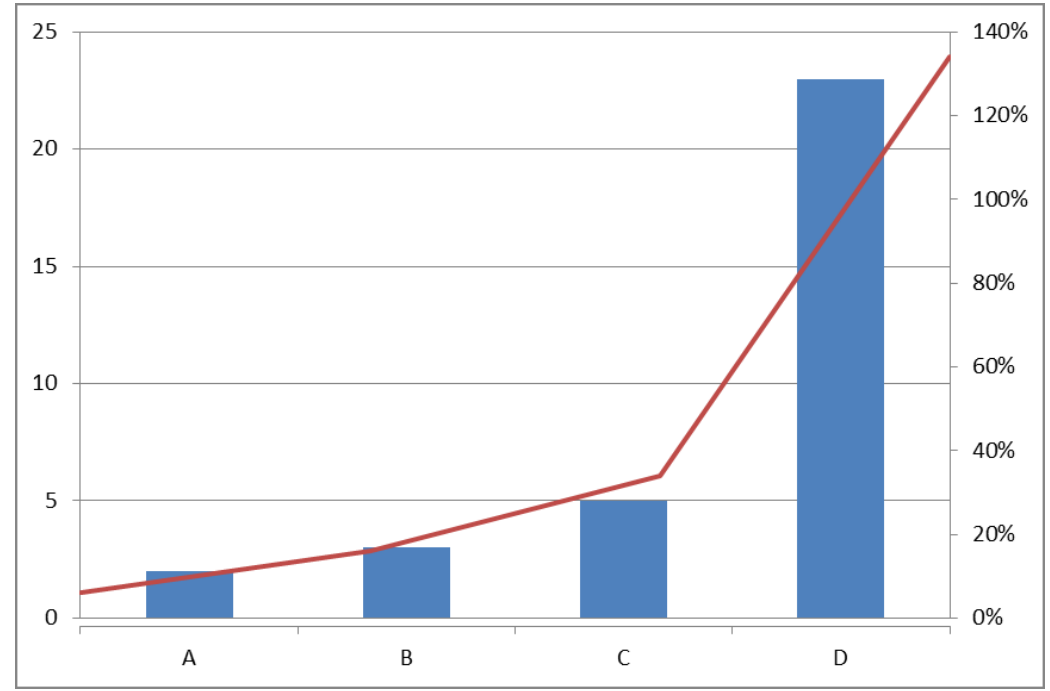

Chart 1: Expressing the percentage of spare part consumption according to categories

\section{Proposal for the optimization process of spare part stockpile of current consumption}

Based on the abovementioned information and the permanent task to deal with the optimization of spare part stockpile, it is obvious that it is a difficult task. In the available materials, there are a few different views of optimization within the MoD. To cope with the optimization successfully, it is possible to use the process designed and shown in the flow cart (Figure 1. Spare parts to support combat operations). An important question is the manner of the spare part storage. Based on the flow chart, it is apparent that the optimization of spare part stockpile cannot be performed separately, but it is necessary to perform it comprehensively. 


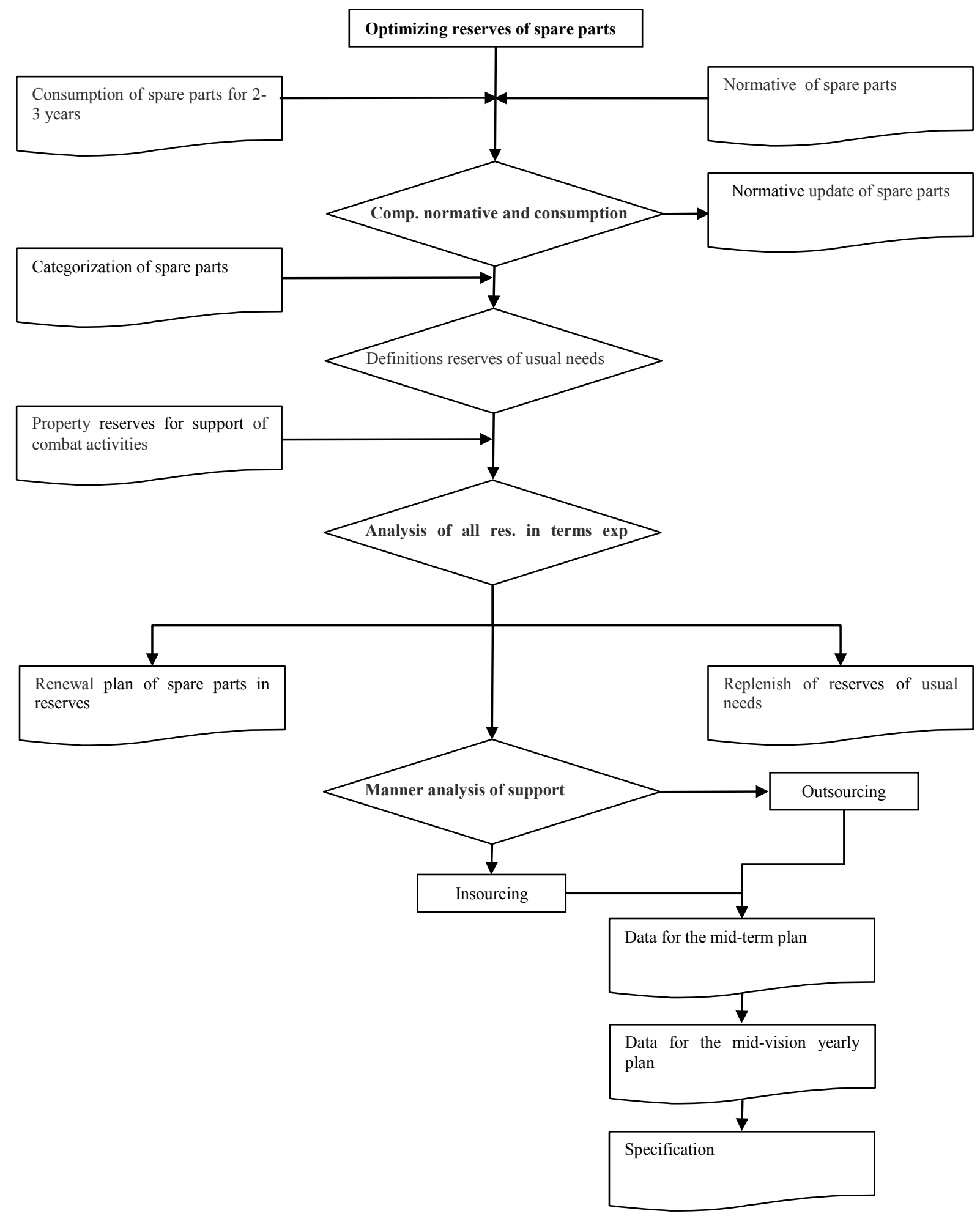

Fig. 1 Processing scheme of optimization reserves 


\section{Conclusions}

The result of investigation is a possible proposal for the spare part categorization according to the three proposed categories that significantly show the necessity of maintaining a spare part stockpile due to the specific tasks performed by the MoD and the ACR. Immediate unavailability of spare parts can cause loss of forces proficiency or, if need be, the insufficient combat readiness in defending the republic. The recent Russian intervention in Ukraine has clearly shown that it is not possible to rely on the claim that we are safe and there is no threat.

Looking at the stockpile only in terms of "dead money on the shelf" is good only for the companies making a profit, not for the companies providing a public service.

\section{Acknowledgements}

This paper was written on base studies that has solve spare parts for equipment of the Army of the Czech Republic in peacetime.

\section{References}

[1] MF. Key performance indicators - operational costs. [online] 2013 [cit. 5. 11. 2013] Available from: http://www.mfcr.czlcs\verejny-sektor\monitoring $\backslash k l i c o v e-u k a z a t e l e-$ vykonnosti-ucetni-vykalklicovy-ukazatel-vykonnosti-nak.

[2] NSA (The NATO Standardization Agency). System life cycle management - AAP 48. Standardization agreement. STANAG 4728. Edition . Brussels, 2012.

[3] OCHRANA, F. Cost utility methods in the public sector. Prague, Ekopress, s.r.o., 2005. ISBN 80-86119-96-3.

[4] KŘİŽEK, P. Cost Assessment of Operation Ground Military Equipment. [Dissertation thesis]. Brno, University of Defense, Faculty Economy and Management, 2014.

[5] Economical Section of MO. Controlling implementation into the MoD units. Čj. 129/2013-8201. Praha, 2013.

[6] MO ACR. Order of the MoD No. 48 ze dne 6. června 2013. Management and disposal with property of the Ministry of Defense. Prague, 2013.

[7] The General Staff of the ACR. Directive - Principles for the development and keeping the stocks of the state property with which the Ministry of Defense dispose. Praha, 2005 in additional Annexes. Čj. 6127-40/2005/DP-3042.

[8] Logistics division of MOD. Analysis and design of procurement of spare parts to repair units equipment and units of the ACR. Praha, 2009. Čj. 123-13/2009-3042.

[9] HLADÍK, T. TULACH, P. Effective management of spare parts in maintenance. [online] 2009 [cit. 12. 9. 2016] Available from: <http://archiv.logio.cz/wpcontent/uploads/2009/11/efektivni-rizeni-zasob-nahradnich-dilu-v-udrzbe.pdf $>$

[10] Logio, s.r.o. Optimization of stock supplies the materials and spare parts for maintenance - Unipetrol. Case study. [online] 2015 [cit. 31. 1. 2017] Available from: $<$ https://logio.cz/unipetrol.html $>$

[11] С̆j. 1706/2008-3042-POM. Directives monitoring and evaluating the coefficient of technical readiness. GST Prague, 2008.

[12] ZIKMUND, M. Pareto (ABC) analysis - a powerful tool in logistics, marketing and business. [online] 2011 [cit. 31. 1. 2017] Available from:< http://www.businessvize.cz/rizeni-a-optimalizace/paretova-abc-analyza-mocny-nastrojv-logistice-marketingu-i-obchodu/pdf $>$

[13] VOCHOZKA, R. Management reserves of spare parts in MoD. [online] 2016 [cit. 31. 1. 2017] Available from: < http://aktivity.unob.cz/dk/Documents/Sborn\% C3\%ADk_Proceedings_\%202016.pdf $>$

[14] Catalog - Normative of spare parts for repair wheeled infantry fighting vehicles "KBVP" and wheel armored transporters of all modifications. MoD of Prague, 2010. Publ. Č. 7301-0601-CZE-00. 